\title{
Impact of thermoelectric cooling modules on the efficiency of a single-phase asynchronous machine
}

\author{
Rupert Gouws
}

Heino van Jaarsveldt

Faculty of Engineering, North-West University, Potchefstroom, South Africa

\begin{abstract}
In this paper, the authors present the impact of thermoelectric cooling modules (TECMs) on the efficiency of a single-phase asynchronous machine. TECMs are used to lower the stator winding temperature and core temperature of the single-phase asynchronous machine. A similar effect might be possible by operating the asynchronous machine in a controlled lower temperature environment or by using other means of improved controlled cooling. An overview on the materials and method used during the experimental setup of the single-phase asynchronous machine with the TECMs is provided. Experimental results on the efficiency analysis, temperature analysis and equivalent circuit parameter analysis are provided. It is shown that the efficiency of the single-phase asynchronous machine can be increased by $4.44 \%$ when cooled by TECMs.
\end{abstract}

Keywords: asynchronous machine, thermoelectric cooling modules, efficiency temperature analysis

\section{Introduction}

Globally around $40 \%$ of the electricity supplied to the industrial (mining) sector is consumed by electric motorised systems and for South Africa around $60 \%$ of the electricity supplied to the industrial (mining) sector is consumed by asynchronous machines (DME, 1998; Mthombeni, 2007). It should be noted that these asynchronous machines also include larger three phase machines, some of them starting out at higher efficiencies, and essentially operate on different principles.

It is therefore important to invest in projects to lower the energy consumption (or improve the effi- ciency) of electric motorised systems and specifically asynchronous machines. In this paper, the efficiency of a single-phase asynchronous machine is improved by the use of thermoelectric cooling modules (TECMs). The TECMs are used to lower the stator winding and core temperature of the singlephase asynchronous machine. The materials and method used during this project is detailed in section 2 and the efficiency analysis results obtained from the experimental setup of the single-phase asynchronous machine is presented in section 3 . In this paper, a single phase asynchronous machine is cooled by means of TECMs, the same method of cooling can also be applied to three phase motors and other electric motorised systems. The size and radically different operating point of the three phase motors may, however, present some difficulty in the design and placement of the cooling system.

The following are only a few methods that exist to effectively determine the efficiency of an asynchronous machine: 1) the segregated losses method, 2) the equivalent circuit method, 3) the slip analysis method, 4) the air gap analysis method, and 5) the current analysis method (Dlamini et al., 2010). It should be noted that in industrial terms efficiency is normally the ratio of the shaft output power to the input power. For this study, we are only interested in the impact of the cooling caused by the TECMs on the efficiency of the asynchronous machine, therefore, we decided to use the equivalent circuit method to determine the efficiency of the asynchronous machine. Gouliaev et al., (1999) provide more detail on high reliability thermoelectric cooling modules and a TECM manufacturing process developed specifically to reduce internal mechanical stresses and to increase system reliability (Gouliaev and Holopkin, 1999). The precise methods and equipment for thermoelectric 


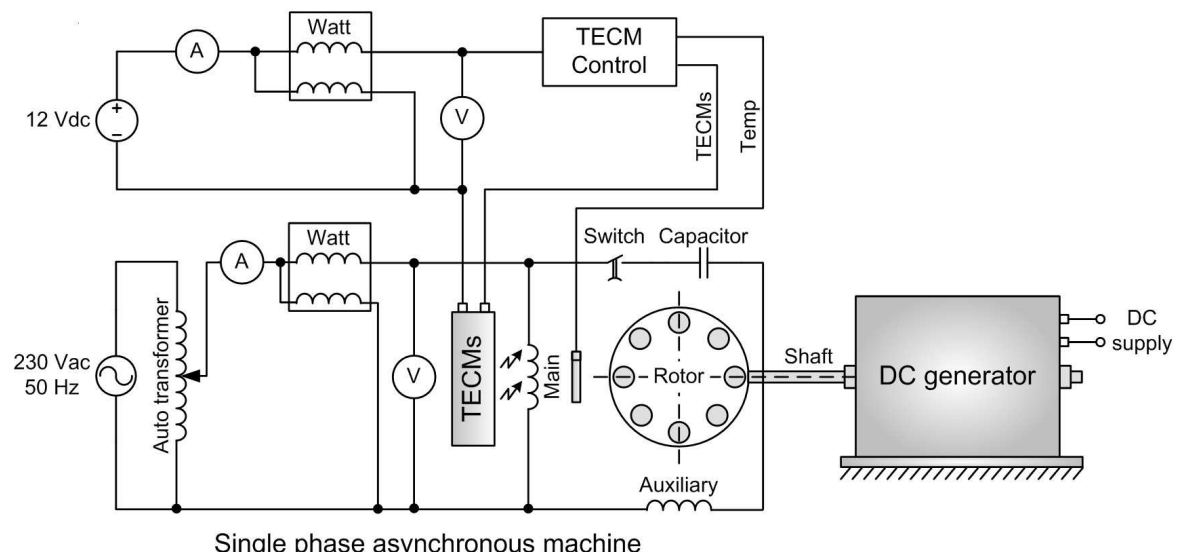

Figure 1: Experimental setup of the asynchronous machine with the TECMs

cooling modules parameters measurement is presented by Anatychuk et al., (1997). Zhang et al. (2010) provide detail on the analysis of thermoelectric cooler performance for high power electronic packages such as processors.

This study specifically focussed on the impact of the TECMs on the efficiency of the single phase asynchronous machine. Further study is, however, required to quantify the economics. The exact savings (return or payback) in energy needs to be quantified against the cost of the TECMs, in order to calculate the economical viability of the project.

\section{Materials and method}

This section provides an overview on the singlephase asynchronous machine and the method used to perform cooling. Figure 1 shows an overview diagram of the experimental setup of the singlephase asynchronous machine with a dc generator connected to the shaft. The dc generator was used as a load on the single-phase asynchronous machine. The output of the dc generator can also be used to power the TECMs.

The single-phase asynchronous machine is capacitor started by means of an auxiliary winding. The main winding is used for continuous (running) operating conditions. The temperature of the main winding (stator winding) of the single phase asynchronous machine is lowered by means of TECMs. The TECMs is supplied with a $12 \mathrm{~V}_{\mathrm{DC}}$ source and is controlled according to the temperature of the main winding. The single-phase asynchronous machine is supplied with a $230 \mathrm{VAC}, 50 \mathrm{~Hz}$ source.

A digital wattmeter, ammeter and voltmeter connected to the terminals of the single-phase asynchronous machine are used to measure the power consumption and determine the parameter of the equivalent circuit. The no-load test and blocked rotor test (or locked rotor test) are performed on the asynchronous machine to determine the parameters of the equivalent circuit. The autotransformer is included in the figure as it forms part of the blocked rotor test. Guru and Hiziroglu (2001) provide more detail on single-phase asynchronous machines and equivalent circuits.

The power consumption of the TECMs is measured separately with another digital wattmeter. The sum of the two digital watt-meters represents the total energy consumption of the single phase asynchronous machine with the TECMs. The power to drive the cooling devices is therefore included in the saving factor. Gouws (2011) provides more detail on the efficiency calculation (analysis) of an asynchronous motor at an industrial plant in South Africa and the simulation model development of an asynchronous motor. More detail on the simulation model of the single phase asynchronous machine in SolidWorks ${ }^{\circledR}$ and the thermal analysis performed on the single phase asynchronous machine by means of the SolidWorks ${ }^{\circledR}$ Flow-Simulation software is presented by van Jaarsveldt (2011).

Figure 2 provides a photo of the single-phase asynchronous machine that was used for this project. From this photo, the stator windings, core and closure can be clearly seen. The single-phase asyn-

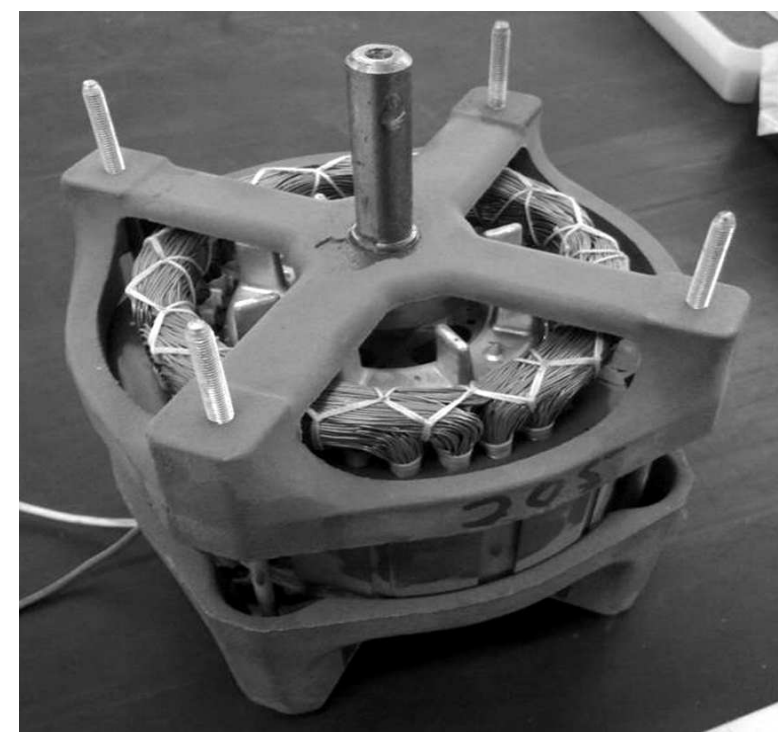

Figure 2: Photo of the single-phase asynchronous machine 
chronous machine has a squirrel cage rotor design, rated output power of $0.22 \mathrm{~kW}$ (or $0.3 \mathrm{Hp}$ ), 4 poles and a rated speed of $1740 \mathrm{rpm}$. The single-phase asynchronous machine further has a slip of $3.33 \%$, a rated torque of $1.12 \mathrm{Nm}$ and a counter clockwise rotation.

Figure 3 shows a SolidWorks ${ }^{\circledR}$ drawing of the stator assembly with the exact placement of the TECMs onto the stator winding. The grey square blocks represent the TECM modules. In this figure, the stator windings and core of the single-phase asynchronous machine is clearly visible. Four TECMs are on the front-end side of the stator assembly. It was possible to only place two TECMs at the back end side of the stator assembly due to a limitation in the available space. A thermal analysis was done in SolidWorks ${ }^{\circledR}$ to determine the exact placement of the TECMs. Van Jaarsveldt (2011) provides more detail on the thermal analysis.

Figure 4 provides a SolidWorks ${ }^{\circledR}$ drawing and a photo of the housing structure for the TECMs. Four TECMs was installed on the front-end side of the single-phase asynchronous machine. The metal

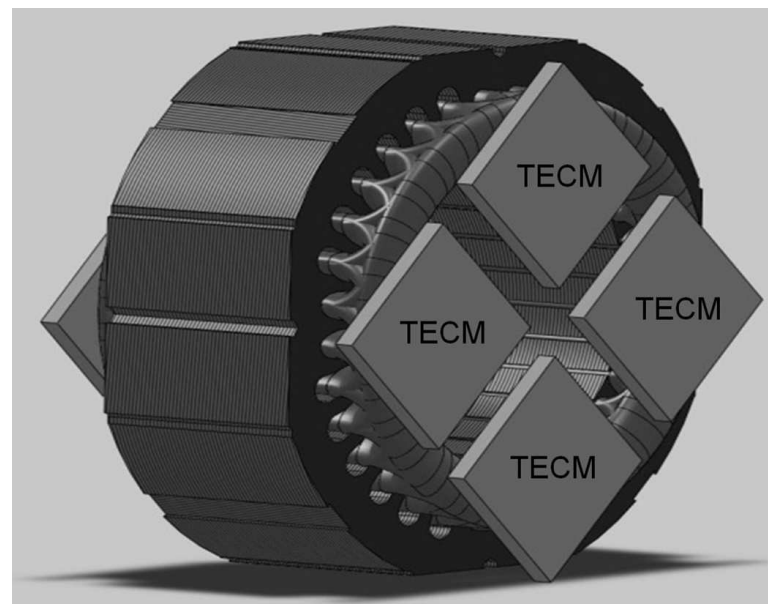

Figure 3: SolidWorks ${ }^{\circledR}$ drawing of the stator assembly with the TECMs
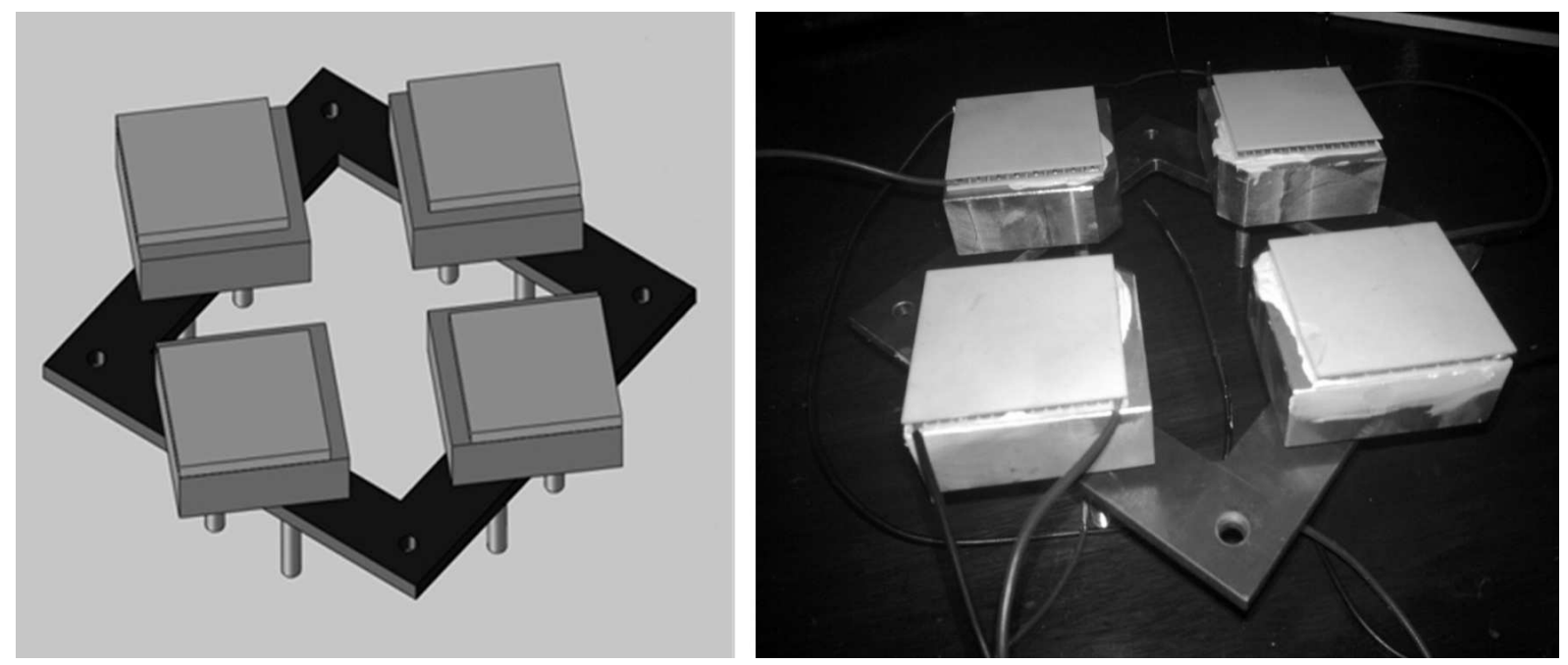

Figure 4: SolidWorks ${ }^{\circledR}$ drawing and photo of the housing structure for the TECMs plate, seen in these figures is bolted directly to the structure of the single-phase asynchronous machine. The TECMs are placed onto the heat sinks by means of thermal paste. The thermal paste services as a medium between the heat sink and the TECM module and improves the dissipation of heat.

Figure 5 shows a photo of the single-phase asynstructure. The single-phase asynchronous machine is cooled by the TECMs on the front end and back end side. The designs done by means of the SolidWorks ${ }^{\circledR}$ Flow-Simulation were used to fabricate and construct the various parts for the final design. The complete system shown in Figure 5 was used as basis to perform the efficiency analysis, temperature analysis, and equivalent circuit analysis. The results obtained from each of these tests are provided in section 3. More detail on the simulation model development of the single phase asynchronous machine done by means of the SolidWorks ${ }^{\circledR}$ Flow Simulation software is presented by van Jaarsveldt (2011).

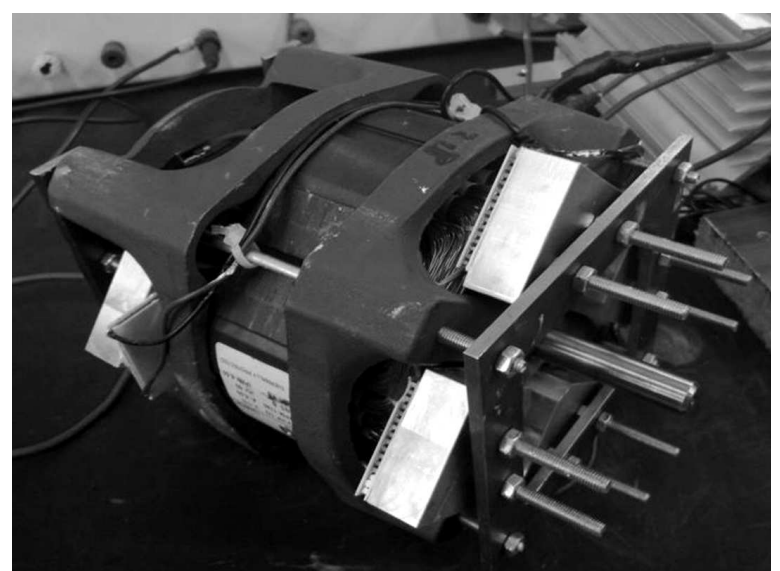

Figure 5: Photo of the single-phase asynchronous machine with the TECM housing structure chronous machine with the installed TECM housing 


\section{Results and discussion}

This section provides the experimental results obtained from the single-phase asynchronous machine with the installation of the TECMs. Table 1 provides the results on the stator temperature and stator resistance test. From this table, it can be seen that the initial stator temperature and initial stator resistance is $24.6^{\circ} \mathrm{C}$ and $3.12 \Omega$, respectively. The readings are recorded in 5-minute intervals and after an hour, the stator temperature and stator resistance has increased to $68.7^{\circ} \mathrm{C}$ and $4.98 \Omega$, respectively. The temperature increased by $44.1^{\circ} \mathrm{C}$ over a period of an hour and the stator resistance increased by $1.86 \Omega$ over the same period.

Table 1: Stator temperature and stator resistance test results

\begin{tabular}{lcc}
\hline Time (minutes) & $\begin{array}{c}\text { Stator } \\
\text { temperature }\left({ }^{\circ} \mathrm{C}\right)\end{array}$ & $\begin{array}{c}\text { Stator } \\
\text { resistance }(\Omega)\end{array}$ \\
\hline Initial & 24.6 & 3.12 \\
\hline 5 & 31.7 & 3.18 \\
\hline 10 & 38.4 & 3.32 \\
\hline 15 & 44.6 & 3.48 \\
\hline 20 & 49.3 & 3.62 \\
\hline 25 & 52.8 & 3.94 \\
\hline 30 & 55.3 & 4.08 \\
\hline 35 & 58.8 & 4.16 \\
\hline 40 & 60.2 & 4.32 \\
\hline 45 & 61.4 & 4.54 \\
\hline 50 & 63.8 & 4.73 \\
\hline 55 & 65.9 & 4.86 \\
\hline 60 & 68.7 & 4.98 \\
\hline
\end{tabular}

Figure 6 provides a graph of the stator resistance against the stator temperature. From this graph, it can be seen that the data follows a second order polynomial of $y=0.0011 x^{2}-0.0565 x+3.8637$, with a $R^{2}$ value of 0.9889 . The $R^{2}$ value obtained for the fit between the measured data and the sec- ond order polynomial represents a very good fit. Griffiths (2005) provide more detail on second order polynomial line fittings (or trend-lines) and the coefficient of determination $\left(\mathrm{R}^{2}\right)$. It can further be seen from this figure that when the stator temperature decreased, the stator resistance also decreased.

Table 2 provides the experimental results for the no-load test. From this table, it can be seen that at an average temperature of $30^{\circ} \mathrm{C}$, the voltage was $100.4 \mathrm{~V}$, the current was $5.80 \mathrm{~A}$, the power factor was 0.22387 and the active power was $130.36 \mathrm{~W}$. When the temperature reached $68.8^{\circ} \mathrm{C}$, the voltage was measured at $100.1 \mathrm{~V}$, the current was $5.75 \mathrm{~A}$, the power factor was 0.24772 and the active power was recorded at $142.58 \mathrm{~W}$.

Table 2: Experimental results for the no-load test

\begin{tabular}{lcccc}
\hline $\begin{array}{l}\text { Temper- } \\
\text { ature }\left({ }^{\circ} \mathrm{C}\right)\end{array}$ & $\begin{array}{c}\text { Voltage } \\
(\mathrm{V})\end{array}$ & $\begin{array}{c}\text { Current } \\
(\mathrm{A})\end{array}$ & $\begin{array}{c}\text { Power } \\
\text { factor }(\theta)\end{array}$ & $\begin{array}{c}\text { Power } \\
(\mathrm{W})\end{array}$ \\
\hline 30 & 100.4 & 5.80 & 0.22387 & 130.36 \\
\hline 40 & 100.6 & 5.83 & 0.23039 & 135.12 \\
\hline 50 & 100.0 & 5.74 & 0.23906 & 137.22 \\
\hline 60 & 100.5 & 5.81 & 0.24339 & 142.12 \\
\hline 68.8 & 100.1 & 5.75 & 0.24772 & 142.58 \\
\hline
\end{tabular}

Table 3 provides the experimental results for the blocked-rotor test. From this table, it can be seen that at an average temperature of $30^{\circ} \mathrm{C}$, the voltage was only $19.60 \mathrm{~V}$, the current was $6.17 \mathrm{~A}$, the power factor was 0.71691 and the active power was $86.70 \mathrm{~W}$. When the temperature reached $68.8^{\circ} \mathrm{C}$, the voltage was measured at $20.67 \mathrm{~V}$, the current was $6.03 \mathrm{~A}$, the power factor was 0.74111 and the active power was recorded at $92.37 \mathrm{~W}$.

Table 4 provides the parameter calculation results for the blocked rotor test. From this table, it can be seen that the leakage reactance's $\left(X_{1}\right.$ and $\left.X_{2}\right)$ and rotor resistance $\left(R_{2}\right)$ was calculated at $1.151 \Omega$

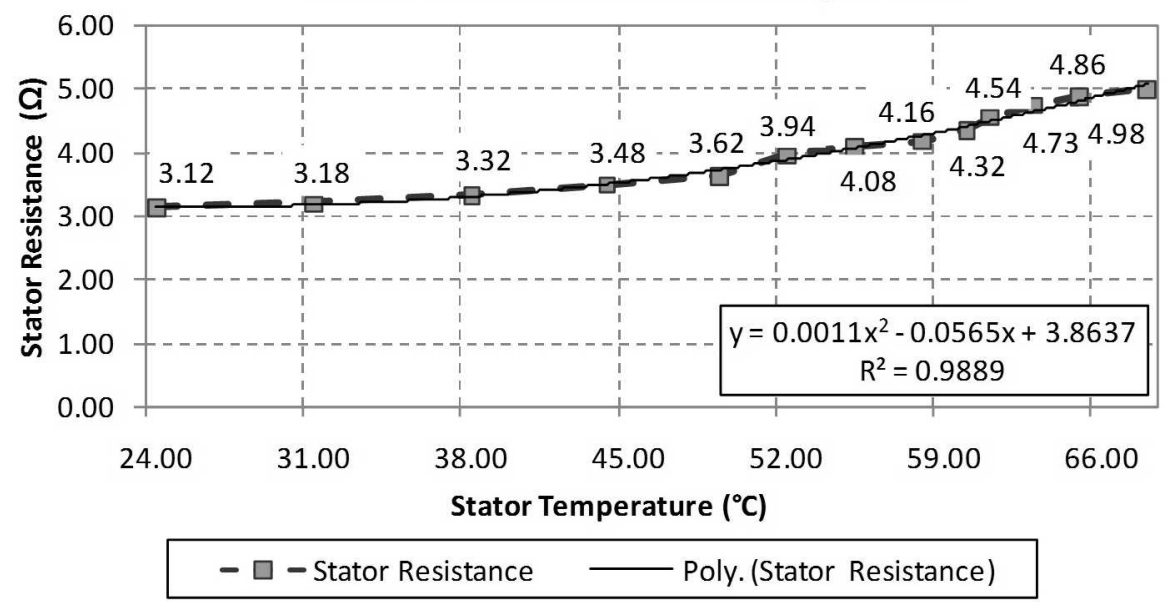

Figure 6: Plot of the stator resistance against the stator temperature 
and $0.170 \Omega$, respectively. The input impedance, total resistance and total reactance for the blocked rotor test were calculated at $3.428 \Omega, 2.540 \Omega$ and $2.301 \Omega$, respectively.

Table 3: Experimental results for the blocked rotor test

\begin{tabular}{lcccc}
\hline $\begin{array}{l}\text { Temper- } \\
\text { ature }\left({ }^{\circ} \mathrm{C}\right)\end{array}$ & $\begin{array}{c}\text { Voltage } \\
(\mathrm{V})\end{array}$ & $\begin{array}{c}\text { Current } \\
(\mathrm{A})\end{array}$ & $\begin{array}{c}\text { Power } \\
\text { factor }(\theta)\end{array}$ & $\begin{array}{c}\text { Power } \\
(\mathrm{W})\end{array}$ \\
\hline 30 & 19.60 & 6.17 & 0.71691 & 86.70 \\
\hline 50 & 20.31 & 6.15 & 0.72901 & 91.06 \\
\hline 60 & 20.47 & 6.08 & 0.73509 & 91.49 \\
\hline 68.8 & 20.67 & 6.03 & 0.74111 & 92.37 \\
\hline
\end{tabular}

Table 4: Parameter calculation results Blocked rotor test

\begin{tabular}{lcc}
\hline Parameter & Description & Value $(\Omega)$ \\
\hline$Z_{b m}$ & Input impedance & 3.428 \\
\hline$R_{b m}$ & Total resistance & 2.540 \\
\hline$X_{b m}$ & Total reactance & 2.301 \\
\hline$X_{1}=X_{2}$ & Leakage reactance & 1.151 \\
\hline$R_{2}$ & Rotor resistance & 0.170 \\
\hline
\end{tabular}

Table 5 provides the parameter calculation results for the no-load test. From this table, it can be seen that the magnetization reactance $\left(X_{m}\right)$ and the rotational loss $\left(P_{r}\right)$ was calculated at $30.280 \Omega$ and 62.814 W, respectively. The impedance, resistance and reactance for the no-load test were calculated at $17.409 \Omega, 4.312 \Omega$, and $16.866 \Omega$, respectively.

Table 6 provides the results on the efficiency analysis of the single-phase asynchronous machine. From this table, it can be seen that when the stator winding temperature is $30^{\circ} \mathrm{C}$, the efficiency of the asynchronous machine is $47.05 \%$. When the temperature rises to $68.8^{\circ} \mathrm{C}$, the efficiency drops to $42.61 \%$. The efficiency therefore increased by $4.44 \%$ when the stator temperature decreased by $38.8^{\circ} \mathrm{C}$ over the provided period.
Table 5: Parameters calculation results no-load test

\begin{tabular}{lcc}
\hline Parameter & Description & Value \\
\hline$Z_{n l}$ & No-load impedance & 17.409 \\
\hline$R_{n l}$ & No-load resistance & 4.312 \\
\hline$X_{n l}$ & No-load reactance & 16.866 \\
\hline$X_{m}$ & Magnetization reactance & 30.280 \\
\hline$P_{r}$ & Rotational loss & 62.814 \\
\hline
\end{tabular}

Figure 7 provides a graph on the machine efficiency against the stator temperature. From this graph, it can be seen that the data follows a second order polynomial of $y=-0.0009 x^{2}-0.0306 x+$ 48.773 , with a $R^{2}$ value of 0.9987 . The $R^{2}$ value of 0.9987 obtained from the fit between the measured data and the second order polynomial represents a very good fit. It can further be seen from this figure that the motor efficiency increased when the stator temperature decreased.

Table 6: Efficiency analysis of the single-phase asynchronous machine

\begin{tabular}{cc}
\hline Stator winding temperature $\left({ }^{\circ} \mathrm{C}\right)$ & Efficiency $(\%)$ \\
\hline 30 & 47.05 \\
\hline 36.3 & 46.62 \\
\hline 40 & 46.04 \\
\hline 50 & 45.06 \\
\hline 60 & 43.79 \\
\hline 68.8 & 42.61 \\
\hline
\end{tabular}

Table 7 provides an efficiency comparison of the single-phase asynchronous machine. From this table, it can be seen that the efficiency of the asynchronous machine was increased from $42.61 \%$ under normal operating condition to $47.05 \%$ under cooled operating condition. The stator temperature under normal operating conditions was calculated at $68.8^{\circ} \mathrm{C}$ and the stator temperature under cooled operating conditions was calculated at $30^{\circ} \mathrm{C}$.

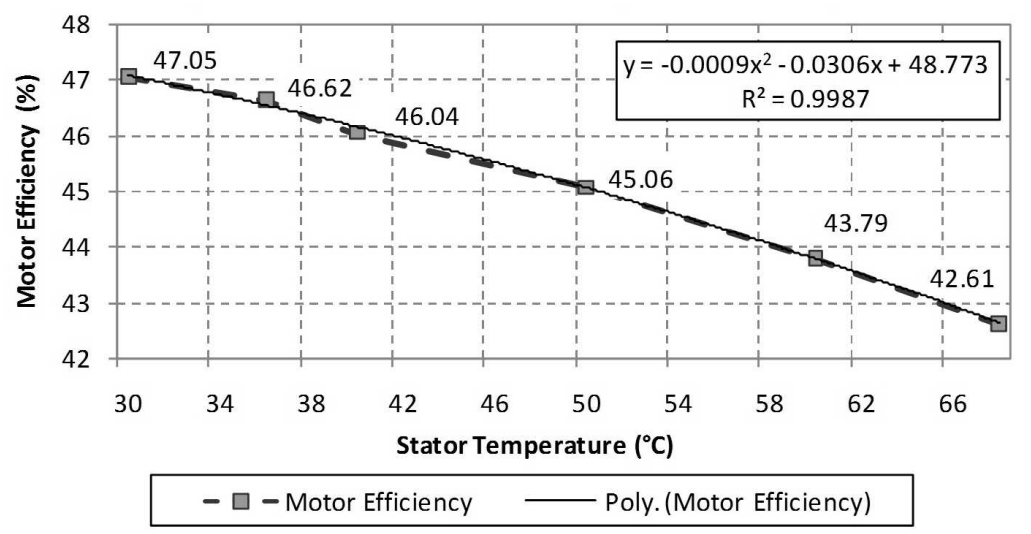

Figure 7: Plot of the asynchronous machine efficiency against the stator temperature 
Table 7: Efficiency comparison of the singlephase asynchronous machine

\begin{tabular}{|c|c|c|c|}
\hline \multicolumn{2}{|c|}{$\begin{array}{c}\text { Normal operating } \\
\text { condition }\end{array}$} & \multicolumn{2}{|c|}{$\begin{array}{c}\text { TECM cooled } \\
\text { operating condition }\end{array}$} \\
\hline $\begin{array}{l}\text { Stator temp- } \\
\text { erature }\left({ }^{\circ} \mathrm{C}\right)\end{array}$ & $\begin{array}{c}\text { Efficiency } \\
\text { (\%) }\end{array}$ & $\begin{array}{l}\text { Stator temp- } \\
\text { erature }\left({ }^{\circ} \mathrm{C}\right)\end{array}$ & $\begin{array}{c}\text { Efficiency } \\
\text { (\%) }\end{array}$ \\
\hline 68.8 & 42.61 & 30 & 47.05 \\
\hline
\end{tabular}

\section{Conclusion}

In this paper, the stator and core temperature of a single-phase asynchronous machine is lowered by means of TECMs. The impact of the cooling (by means of the TECMs) on the efficiency of the single-phase asynchronous machine was presented. The experimental results included an efficiency analysis, temperature analysis and equivalent circuit analysis. It is shown that when the stator temperature increased, the stator resistance increased, but the machine efficiency decreased. When the stator temperature was decreased by the TECMs the stator resistance decreased, which in turn, increased the efficiency of the single phase asynchronous machine. The TECMs also has an influence on the core temperature of the single-phase asynchronous machine. The efficiency of the single-phase asynchronous machine was increased from $42.61 \%$ under normal operating condition to $47.05 \%$ under cooled operating condition (by means of the TECMs). The efficiency of this specific single-phase asynchronous machine was therefore increased by $4.44 \%$.

It should be noted that the class of machine selected for this study is normally used because they are cheap, reliable, and small and generally only drive small loads. The efficiency of these types of single-phase asynchronous machines is generally not a selection criterion. A larger percentage efficiency increase is required to justify the cost of the TECMs and to make the system economically viable. Further study is required to calculate the exact impact of the TECMs (and cooling in general) on larger three-phase machines, which are normally more efficient to start with. The impact of TECMs (and cooling) on three phase machines working in closed environments where other means of cooling (typically air) is not available will also provide an interesting study.

Van Jaarsveldt (2011) presents more detail on the efficiency analysis of the asynchronous machine. Huai et al., (2003) provide detail on the computational analysis of the temperature rise phenomena in electric asynchronous motors and Wang et al., (2010) provide detail on a single-phase asynchronous motor with series connected windings and capacitors.

\section{References}

Anatychuk L.I., Varich N.I., and Shchedrin A.A., (1997). Precise methods and equipment for thermoelectric cooling modules parameters measurement, Proceedings of the International Conference on Thermoelectrics (ICT '97), August 1997, pp. 672675.

Dlamini V., Naidoo R., and Manyage M., (2010). Practical evaluation of motors efficiency estimation techniques, Proceedings of the International Conference on the Industrial and Commercial Use of Energy (ICUE), August 2010, pp. 3-9.

DME, (1998). White Paper on the Energy Policy of the Republic of South Africa (RSA), Department of Minerals and Energy, December 1998, ISBN: 09584235-8-X.

Gouliaev A., and Holopkin A., (1999). High reliability thermoelectric cooling modules, 18th International Conference on Thermoelectrics, August 1999, pp. 319-320.

Gouws R., (2011). Efficiency analysis of an induction motor with direct torque and flux control at a hot rolling mill, Proceedings of the International Conference on the Industrial and Commercial Use of Energy (ICUE), August 2011, pp. 63-68.

Griffiths I.W., (2005). Principles of biomechanics and motion analysis, Lippincott Williams \& Wilkins, October 2005.

Guru B.S., and Hiziroglu H.R., (2001). Electric machinery and transformers, Oxford Press, New York, 2001.

Huai Y., Melnik R.V.N., and Thogersen P.B., (2003). Computational analysis of temperature rise phenomena in electric induction motors, Applied Thermal Engineering, Vol. 23, May 2003, pp. 779-795.

Mthombeni T.L., (2007). Energy efficient motor systems for Eskom demand side management, Proceedings of the International Conference on the Industrial and Commercial Use of Energy (ICUE), August 2007, pp. 19-24.

Van Jaarsveldt J.H., (2011). Cooling and energy efficiency, Project document, North-West University, November 2011.

Wang X., Zhong H., Yang Y., and Mu X., (2010). Study of a novel energy efficient single-phase induction motor with three series-connected windings and two capacitors, IEEE Transactions on Energy Conversion, Vol. 25, June 2010, pp. 433-440.

Zhang H.Y., Mui Y.C., and Tarin M., (2010). Analysis of thermoelectric cooler performance for high power electronic packages, Applied Thermal Engineering, Vol. 30, May 2010, pp. 561-568.

Received 1 November 2012; revised 15 January 2014 